\title{
P-1201 - ANTIPSYCHOTIC THERAPY AND BIOCHEMICAL LABORATORY PROFILE CHARACTERIZATION OF A SAMPLE OF PATIENTS DIAGNOSED WITH SCHIZOPHRENIA
}

\author{
M.Amorim, A.Moreira, J.Condeco, P.Monteiro, A.J.Marques, T.Summavielle \\ ${ }^{1}$ Laboratório de Reabilitação Psicossocial, Faculdade de Psicologia e de Ciências da Educação da \\ Universidade do Porto e Escola Superior de Tecnologia da Saúde do Instituto Politécnico do Porto, ${ }^{2}$ \\ Instituto de Ciências Biomédicas Abel Salazar, Universidade do Porto, ${ }^{3}$ Escola Superior de \\ Tecnologia da Saúde do Instituto Politécnico do Porto, ${ }^{4}$ Instituto de Biologia Molecular e Celular, \\ Porto, Portugal
}

Introduction: Schizophrenia (SCZ) patients are reported to present significant abnormalities in lipid and glucose metabolism, that increase the risk for cardiovascular disease and diabetes, possibly induced by antipsychotic therapy (APT) and lifestyle.

Objectives/Aims: Characterize a sample of SCZ patients relating APT and biochemical laboratory profile.

Methods: We conducted a retrospective longitudinal study of SCZ patients' records from Psychiatry Service of Hospital S.João (Porto, Portugal) from 2009 to 2011.

Results: The study included 51 SCZ patients of which $82.4 \%(n=42)$ were male, presenting a mean age of $39.3 \pm 9.2$ years. The most frequent subtype of SCZ was paranoid $(90.0 \%)$. The average age of diagnosis was $24.5 \pm 8.4$ years old. Oral APT was prescribed to 48 patients. Depot APT were prescribed to 40 patients. Haloperidol and risperidona were in both cases the most frequent drugs. $50 \%$ of patients presented high total cholesterol values ( $\geq 200 \mathrm{mg} / \mathrm{dL}$ ), $25 \%$ high LDL cholesterol ( $\geq 160 \mathrm{mg} / \mathrm{dL}), 81 \%$ low HDL cholesterol $(\leq 40 / 50 \mathrm{mg} / \mathrm{dL})$ and $44 \%$ presented high triglycerides results ( $\geq 150 \mathrm{mg} / \mathrm{dL}$ ). $27 \%$ of patients presented impaired fasting glucose values (110 to $125 \mathrm{mg} / \mathrm{dl}$ ) and $27 \%$ presented at least one plasma glucose result that meet the criteria for diabetes diagnosis ( $\geq 126 \mathrm{mg} / \mathrm{dl}$ ). There was an overall increase in hepatic enzymes (54\% ALT, 36\% AST and GGT).

Conclusions: Hepatic metabolism of APT may explain elevated liver enzimes. Lipid and glucose profiles in our sample clearly indicate the need of monitoring SCZ patients, managing APT side effects and lowering risk. We encourage clinicians to record metabolic monitoring and to establish corrective measures (food, lifestyle and medication). 